УДК 669.18

О.С. Лантух, аспірант, shurik.dp.ua@gmail.com

Л.С. Молчанов, канд. техн. наук, доцент, kaf.stal@metal.nmetau.edu.ua

Є.В. Синегін, канд. техн. наук, доцент, kaf.stal@metal.nmetau.edu.ua

Національна Металургійна академія України, м. Дніпро

\title{
МЕТОДИКА ФІЗИЧНОГО МОДЕЛЮВАННЯ СПЛИВАННЯ АНСАМБЛЮ НЕМЕТАЛЕВИХ ВКЛЮЧЕНЬ У СТАЛЕРОЗЛИВНОМУ КОВШ
}

У статті запропонована методика фізичного моделювання спливання неметалевих включень у сталі за час їі випуску і витримки. Визначені критерії подоби і масштаби фізичного моделювання. Висунута гіпотеза, яка дозволяс імітувати процес вспливання у сталі неметалевих включень розмірами менше за 300 мкм. Вибрані модельні речовини для моделювання.

Ключові слова: фізичне моделювання, неметалеві включення, автомодельність, критерій Архімеда, критерій гомохронності.

In the article a methodology of physical simulation of floating in liquid steel the nonmetallic inclusions during tapping and holding has been suggested. The simulation numbers and the scales of physical simulation were defined. In order to simulate the floating in steel the nonmetallic inclusions up to $300 \mu \mathrm{m}$ the hypothesis was put forward. The substances for simulation were chosen.

Keywords: physical modeling, nonmetallic inclusion, self-similarity, Archimedes number, number of homochronality.

\section{Постановка проблеми}

Неметалічні включення (НВ) у сталі є не лише концентраторами внутрішніх напружень, а й за певних умов можуть створювати умови до корозійного руйнування сталі [1]. 3 огляду на особливості виробництва сталі в умовах сучасного металургійного виробництва необхідно відзначити, що основними джерелами забруднення залізовуглецевого напівпродукту НВ на стадії його випуску з кисневого конвертера у ківш $є$ пічні шлаки, фрагменти футерівки ковша й продукти розкислення й легування.

Видалення неметалевих включень зі сталі відбувається за рахунок Архімедової сили і конвекційного руху потоків металу. При цьому для малих НВ переважає вплив конвекції, а для крупних - Архімедової сили [2]. Інтенсифікацію цього процесу здійснюють шляхом пришвидшення висхідних потоків розплаву за допомогою продувки або електромагнітного перемішування. Проте застосування цих заходів для ковшів малої ємності є недоцільним через значні теплові втрати і небезпеку затягування шлакових включень 3 покривного шлаку назад у метал при вдуванні аргону. Електромагнітна ж обробка вимагає значних капітальних витрат на іiі впровадження. Тому єдиним технологічно-доцільним способом рафінування сталі від НВ у таких умовах залишається витримка металевого розплаву у ковші.

Аналіз останніх досліджень та публікацій

Найбільш розповсюдженими методами по боротьбі з неметалевими включеннями є розробка раціональних технологій розкислення сталі, та оптимізація режимів ії позапічної обробки, серед яких найбільшою ефективністю зарекомендувала себе продувка сталі інертним газом [3]. Перші спрямовані лише на зменшення забруднення сталі ендогенними НВ, що досягається шляхом створення умов для їх укрупнення або модифікації наданням їм сферичної форми $[4,5]$. Хороших результатів з запобігання утворення в сталі ендогенних НВ досягають при розкисленні сталі вуглецем під вакуумом [6].

Видалення екзогенних НВ здійснюється переважно шляхом поліпшення умов їх вспливання продувкою аргоном, що водночас супроводжується небезпекою оголення дзеркала металу та його вторинного окислення [3]. Для сталерозливних ковшів невеликої ємності продувка аргоном не завжди є економічно доцільною і єдиним способом видалення екзогенних НВ, які утворюються при контакті металу з вогнетривами і шлаковою фазою $є$ витримка сталі в ковші перед розливкою. 


\section{Формулювання мети дослідження}

Спливання одиночної часточки в рідині описується законом Стокса. Однак з низки причин, зокрема спливання ансамблю часточок за умов інтенсивного руху потоків спричинених випуском сталі з плавильного агрегату, закон Стокса порушується $[7,8]$.

Дослідження процесу вспливання ансамблю НВ у розплаві методами комп’ютерного і математичного моделювання є вкрай складним. Найкращим варіантом для досягнення цієї мети $\epsilon$ фізичне моделювання. Метою дослідження $є$ підготовка фізичного моделювання для визначення особливостей вспливання ансамблю НВ у рідкій сталі.

\section{Виклад основного матеріалу}

У якості цільової функції в рамках дослідження, що проводилося, була обрана тривалість $\left(\boldsymbol{\tau}_{\text {hold }}\right)$ вспливання НВ в сталерозливному ковші за час витримки сталі в ковші. Згідно 3 законом Стокса та логічних міркувань на обрану цільову функцію мають вплив наступні фактори: діаметр НВ $\left(\boldsymbol{d}_{\boldsymbol{i n c l}}\right)$, висота $\left(\boldsymbol{h}_{\text {liq }}\right)$ рідини в ковші, густина рідини $\left(\boldsymbol{\rho}_{\text {liq }}\right)$, густина НВ $\left(\boldsymbol{\rho}_{\text {incl }}\right)$, прискорення вільного падіння $(\boldsymbol{g})$, в'язкість рідини $\left(\boldsymbol{v}_{\text {liq }}\right)$ та тривалість наповнення ковша $\left(\boldsymbol{\tau}_{\text {tap }}\right)$. Отримана функціональна залежність матиме вигляд

$$
\tau_{\text {hold }}=f\left(d_{\text {incl }}, h_{\text {liq }}, \rho_{\text {liq }}, \rho_{\text {incl }}, g, v_{l}, \tau_{\text {tap }}\right), \mathrm{c} .
$$

Для зручності замінимо $\left(\boldsymbol{\rho}_{\boldsymbol{i n c l}}\right)$ на різницю густини рідини і $\mathrm{HB}(\boldsymbol{\Delta \rho})$. Загалом у розмірності присутні $N=8$ параметрів, 3 яких $n=5$ параметрів різної фізичної природи. До їх розмірності входять $r=3$ первинні одиниці вимірювання: кг, м, с. Тому загальна кількість безрозмірних комплексів, що визначають розглянуту систему становить

$$
\Pi=N-r=8-3=5 .
$$

Безрозмірні критерії, які характеризують залежність (1) та порядок їх величин для попередньої оцінки їх значущості наведено у таблиці 1. Розглянемо отримані критерії.

Критерій Галілея $(\mathbf{G a}) \epsilon$ мірою відношення сил молекулярного тертя і гравітації в потоці. Порядок величини цього критерію для даних умов є досить великим, що може вказувати на його незначущість.

Таблиця 1. Формування безрозмірних критеріїв

\begin{tabular}{|c|c|c|c|c|c|}
\hline Параметр & $\begin{array}{c}\text { Величина } \\
\text { параметра }\end{array}$ & $\begin{array}{c}\text { Одиниця } \\
\text { вимірювання }\end{array}$ & Масштаб & $\begin{array}{c}\text { Безрозмірний } \\
\text { критерій }\end{array}$ & $\begin{array}{c}\text { Величина } \\
\text { критерію }\end{array}$ \\
\hline $\boldsymbol{\tau}_{\text {hold }}$ & $10^{2}$ & $\mathrm{c}$ & - & Ho' $_{\text {hold }}^{\prime}=\frac{\tau_{\text {hold }}^{2} \cdot g}{h_{\text {liq }}}$ & $10^{5}$ \\
\hline $\boldsymbol{d}_{\text {incl }}$ & $10^{-5} \div 10^{-3}$ & $\mathrm{M}$ & - & $\mathrm{D}=\frac{d_{\text {lincl }}}{h_{\text {liq }}}$ & $10^{-5} \div 10^{-3}$ \\
\hline $\boldsymbol{h}_{\text {liq }}$ & $10^{0}$ & $\mathrm{M}$ & $\mathrm{M}$ & - & - \\
\hline $\boldsymbol{\rho}_{\text {liq }}$ & $10^{3}$ & $\mathrm{\kappa} / \mathrm{M}^{3}$ & $\mathrm{\kappa} \Gamma$ & - & - \\
\hline $\boldsymbol{\Delta} \boldsymbol{\rho}$ & $10^{3}$ & $\mathrm{\kappa} / \mathrm{M}^{3}$ & - & $\mathrm{P}=\frac{\Delta \rho}{\rho_{\text {liq }}}$ & $10^{0}$ \\
\hline $\boldsymbol{g}$ & $10^{1}$ & $\mathrm{M} / \mathrm{c}^{2}$ & $\mathrm{c}$ & - & - \\
\hline $\boldsymbol{v}_{\text {liq }}$ & $10^{-6}$ & $\mathrm{~m}{ }^{2} / \mathrm{c}$ & - & $\mathrm{Ga}=\frac{g \cdot h_{\text {liq }}^{3}}{v_{\text {liq }}^{2}}$ & $10^{13}$ \\
\hline $\boldsymbol{\tau}_{\text {tap }}$ & $10^{2}$ & $\mathrm{c}$ & - & $\mathrm{Ho}_{\text {tap }}^{\prime}=\frac{\tau_{\text {tap }}^{2} \cdot g}{h_{\text {liq }}}$ & $10^{5}$ \\
\hline
\end{tabular}

Симплекс густини (P) є мірою Архімедової сили, яка діє на НВ в розплаві. Дотримання цього симплексу на моделі є доволі складним, оскільки вимагає використання рідин з високою 
густиною, або порошків 3 низькою для імітації НВ. Для спрощення моделювання помножимо симплекс густини на критерій Галілея та лінійний симплекс (D) у третьому ступені.

$$
\mathrm{Ar}=\mathrm{P} \cdot \mathrm{Ga} \cdot \mathrm{D}^{3}=\frac{\Delta \rho}{\rho_{l i q}} \cdot \frac{g h_{l i q}^{3}}{v_{l i q}^{2}} \cdot\left(\frac{d_{\text {incl }}}{h_{\text {liq }}}\right)^{3}=\frac{\Delta \rho \cdot g \cdot d_{\text {incl }}^{3}}{\rho_{\text {liq }} \cdot v_{\text {liq }}^{2}} .
$$

Величина отриманого критерію складає $10^{-1} \div 10^{6}$. Він характеризує відношення підйомних сил, що діють на НВ, до сили в'язкого тертя, які заважають її спливанню.

Критерій (Но') є модифікованим критерієм гомохронності (Нo' $\equiv \mathrm{Ho}: \mathrm{Fr})$, який є безрозмірним часом. Таким чином функціональна залежність (1) у безрозмірній формі має вигляд

$$
\mathrm{Ho}^{\prime}{ }_{\text {hold }}=f\left(\mathrm{D}, \mathrm{Ar}, \mathrm{Ho}_{\text {tap }}^{\prime}\right) \text {. }
$$

Масштаби моделювання були розраховані з використанням двох критеріїв: Архімеда $\mathrm{i}$ модифікованого критерію гомохронності. Для зручності моделювання були довільно обрані масштаби густини матеріалів $\left(\boldsymbol{k}_{\text {pliq }}\right.$ і $\left.\boldsymbol{k}_{\boldsymbol{p} \text { incl }}\right)$ та в'язкості рідини $\left(\boldsymbol{k}_{\boldsymbol{v}}\right)$, відповідно до яких величини лінійного масштабу $\left(\boldsymbol{k}_{l}\right)$ і масштабу часу $\left(\boldsymbol{k}_{\tau}\right)$ визначаються з системи рівнянь

$$
\left\{\begin{array}{l}
k_{\rho l i q} \cdot k_{l}^{3} \cdot k_{\rho i n c l}^{-1} \cdot k_{v}^{-2}=1, \\
k_{\tau}^{2} \cdot k_{l}^{-1}=1 .
\end{array}\right.
$$

У таблиці 2 наведені масштаби всіх факторів для випадків використання у якості рідини, що імітує рідку сталь, води і олії, а НВ - стеарин. 3 аналізу таблиці помітно, що розрахований лінійний масштаб моделі є доволі незручним, оскільки вимагає створення моделі, яка у 1,5 (а для олії - у 30) разів більше натурального об'єкта. Зменшення лінійного масштабу шляхом вибору інших речовин вимагає суттєвого зменшення густини порошку, збільшення густини рідини або зменшення ії в’язкості. На практиці вибір таких речовин є неможливим.

Таблиия 2. Масштаби обраних факторів

\begin{tabular}{|l|c|c|c|c|c|}
\hline \multirow{2}{*}{ Речовина } & \multicolumn{3}{|c|}{ Прийняті } & \multicolumn{2}{c|}{ Розраховані } \\
\cline { 2 - 6 } & $P_{\text {liq }}$ & $P_{\text {incl }}$ & $v_{\text {liq }}$ & $l$ & $\tau$ \\
\hline Вода & 0,14 & 0,26 & 1,37 & $\underline{1,52}$ & 1,24 \\
\hline Олія & 0,13 & 0,39 & 96,19 & $\underline{30,42}$ & 5,52 \\
\hline
\end{tabular}

За для уникнення цієї незручності вводимо поняття локального лінійного масштабу, тобто лінійний масштаб для характерних розмірів ковша $\left(\boldsymbol{h}_{\text {liq }}\right)$ і $\mathrm{HB}\left(\boldsymbol{d}_{\boldsymbol{i n c l}}\right)$ буде розраховуватися окремо. Це, вочевидь, призводить до порушення умови $\mathrm{D}=i d e m$ i необхідності доведення автомодельності або незначущості цього лінійного симплекса.

Попередньо розглянемо область визначення кожного з обраних критеріїв для реальних і лабораторних умов. У таблиці 3 наведені області визначення обраних критеріїв для натури та моделі ковша висотою 2342 мм (ємністю 60 т) та 240 мм відповідно. Діапазони зміни діаметра $\mathrm{HB}$ на моделі визначали 3 умови $\mathrm{Ar}=i d e m$, а часу наповнення моделі ковша -3 умови $\mathrm{Ho}_{\text {tap }}^{\prime}=$ idem . Виходячи з розрахованого таким чином діаметра НВ була розрахована область визначення лінійного симплексу (D) для моделі ковша із використанням у якості рідини, що імітує сталь, води або олії.

Розглянемо детально область визначення лінійного симплексу D (рис. 1). 3 графіку видно, що для води і сталі справедливе твердження $D_{\text {steel }} \cap D_{\text {water }}=\left[9,5 \cdot 10^{-5} ; 1,3 \cdot 10^{-3}\right]$, тобто у лабораторних умовах моделювання процесу $є$ адекватним лише для НВ розміром понад 255 мкм. Для адекватної імітації вспливання включень менших розмірів необхідне підтвердження автомодельності лінійного симплексу (D) в області $\mathrm{D}<9,5 \cdot 10^{-5}$. 
Таблиия 3. Область визначення отриманих критеріїв та факторів, що до них входять

\begin{tabular}{|c|c|c|c|}
\hline \multirow{2}{*}{ Параметр } & \multicolumn{3}{|c|}{ Область визначення } \\
\hline & сталь & вода & олія \\
\hline$d_{i n c}$, МКм & $15 \div 3000$ & $26 \div 5200$ & $456 \div 91300$ \\
\hline$h_{\text {liq }}, \mathrm{M}$ & 2,342 & 0,240 & 0,240 \\
\hline$\rho_{\text {liq }}, \mathrm{\kappa} \Gamma / \mathrm{M}^{3}$ & 7200 & 1000 & 926 \\
\hline$\rho_{\text {incl }}, \mathrm{\kappa} \Gamma / \mathrm{M}^{3}$ & 2300 & 900 & 900 \\
\hline$g, \mathrm{M} / \mathrm{c}^{2}$ & 9,81 & 9,81 & 9,81 \\
\hline$v_{\text {liq }}, \mathrm{m}^{2} / \mathrm{c}$ & $6,3 \cdot 10^{-7}$ & $8,7 \cdot 10^{-7}$ & $6,1 \cdot 10^{-5}$ \\
\hline$\tau_{\text {tap }}, \mathrm{c}$ & $60 \div 180$ & $19 \div 58$ & $19 \div 58$ \\
\hline \multicolumn{4}{|c|}{ Критерії } \\
\hline $\mathrm{Ar}$ & \multicolumn{3}{|c|}{$2,61 \cdot 10^{-1} \div 2,09 \cdot 10^{6}$} \\
\hline $\mathrm{D}$ & $6,4 \cdot 10^{-6} \div 1,3 \cdot 10^{-3}$ & $1,1 \cdot 10^{-4} \div 2,2 \cdot 10^{-2}$ & $1,9 \cdot 10^{-3} \div 3,8 \cdot 10^{-1}$ \\
\hline $\mathrm{Ho}_{\text {tap }}$ & \multicolumn{3}{|c|}{$1,51 \cdot 10^{4} \div 1,36 \cdot 10^{5}$} \\
\hline
\end{tabular}

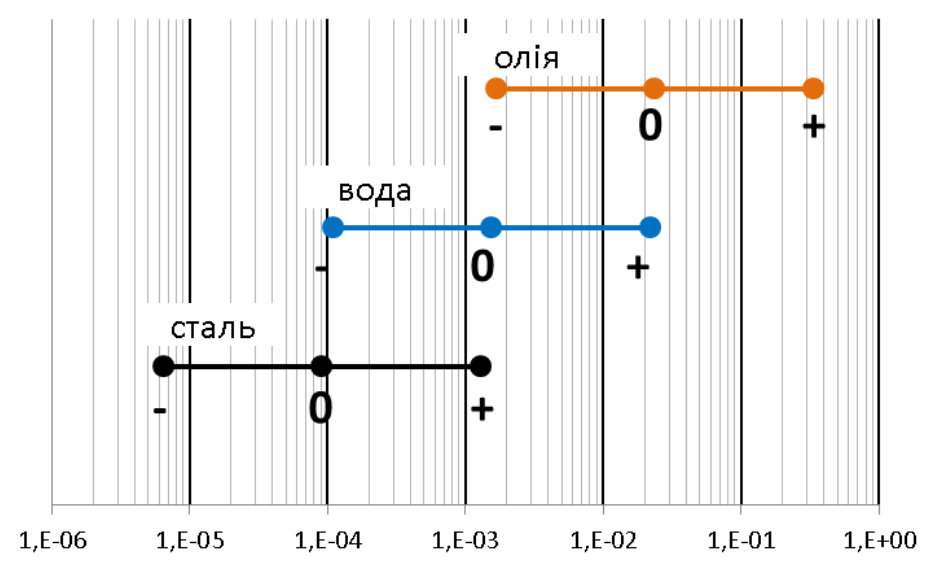

Рuc. 1. Область визначення лінійного симплекса D для сталі, води і олії (знаки “-”, “0” та “+” на прямих це рівні варіювання фактору для експерименту)

Використання олії для моделювання є недоцільним, оскільки області визначення лінійного симплексу для рідкої сталі і для олії не перетинаються.

На наступному етапі було визначено план експерименту. Оскільки математична модель процесу у критеріальній формі завжди є ступеневою функцією, то кожен з критеріїв необхідно варіювати на трьох рівнях: нижньому, нульовому і верхньому. Для визначення коефіцієнтів регресії ступеневої функції необхідно перевести ії до лінійного вигляду шляхом логарифмування. Таким чином, з урахуванням цього переходу величину нульового рівня кожного фактору визначаємо за формулою

$$
\pi_{o}=10 \frac{\lg \pi_{\min }+\lg \pi_{\max }}{2} .
$$

де $\pi_{\min }$ i $\pi_{\max }$ - відповідно мінімальна і максимальна величина критерію. лиці 4.

Розраховані за формулою (6) нульові рівні критеріїв та їх стандартизація наведені в таб-

Таблиия 4. Стандартизація факторів та визначення нульового рівня критеріїв

\begin{tabular}{|l|c|c|c|}
\hline Рівень & $\mathbf{X}_{\mathbf{1}}=\mathbf{l g} \mathbf{A r}$ & $\mathbf{X}_{\mathbf{2}}=\mathbf{l g} \mathbf{H o}_{\mathbf{m}}$ & $\mathbf{X}_{\mathbf{3}}=\mathbf{l g} \mathbf{D}$ \\
\hline Верхній & 6,32 & 5,13 & $-1,66$ \\
\hline Нульовий & 2,87 & 4,66 & $-2,81$ \\
\hline Нижній & $-0,58$ & 4,18 & $-3,96$ \\
\hline
\end{tabular}


Кількість дослідів в плані повного факторного експерименту (ПФЕ) для трьох рівнів варіювання трьох факторів складає $3^{3}=27$ дослідів.

Масу порошку $\left(\boldsymbol{m}_{\text {powder }}\right)$ для моделювання визначаємо з умови рівності об'ємної концентрації порошку на моделі і натурі $V_{\text {incl }} / V_{\text {steel }}=V_{\text {powder }} / V_{\text {water }}$. Розписавши об'єм через густину та масу й виразивши з пропорції вагу порошку отримуємо

$$
m_{\text {powder }}=m_{\text {water }} \cdot \frac{m_{\text {incl }}}{m_{\text {steel }}} \cdot \frac{\mathrm{P}_{\text {model }}}{\mathrm{P}_{\text {origin }}}, \mathrm{\kappa},
$$

де $V_{\text {incl }}, V_{\text {steel }}, V_{\text {powder }}, V_{\text {water }}$ - об'єм відповідно НВ (загальний), сталі в ковші, порошку (загальний) та води на моделі, ${ }^{3} ; m_{\text {incl }}, m_{\text {steel }}, m_{\text {powder }}, m_{\text {water }}$ - маса відповідно НВ (загальна), сталі в ковші, порошку (загальна) та води на моделі, кг; $\mathrm{P}_{\text {model }}, \mathrm{P}_{\text {origin }}$ - симплекс густини для моделі і натури відповідно (див. табл. 1).

\section{Висновки та перспективи подальших досліджень}

Наступним етапом досліджень передбачено проведення фізичного моделювання, яке має на меті підтвердження гіпотези стосовно автомодельності лінійного симплекса. За результатами моделювання можливі 3 варіанти: 1) підтвердження гіпотези; 2) спростування гіпотези; 3) часткове підтвердження гіпотези.

У разі підтвердження гіпотези про автомодельність лінійного симплексу, за результатами проведеного експерименту визначають математичну модель, яка описує тривалість спливання НВ у сталі в залежності від критеріїв Архімеда і гомохронності.

Спростування гіпотези вимагає створення спеціальних умов проведення експерименту: побудови моделі більших масштабів, вибору інших модельних речовин тощо.

У разі часткового підтвердження гіпотези лінійний симплекс $є$ автомодельним лише у певному діапазоні значень, тобто результати моделювання будуть справедливі лише у обмеженому діапазоні розмірів НB.

\section{Список використаної літератури}

1. Филиппов Г.А. Коррозионная стойкость стальных трубопроводов / Г.А. Филиппов, П.Г. Родионова, О.Н. Бакланова // Технология металлов. - 2004. - № 2. - С.24-27.

2. Теорія металургійних процесів [Підручник] / В.Б. Охотський, О.Л. Костьолов, В.К. Сімонов [та ін.]. - К.: ІЗМН, 1997. - 512 с.

3. Технології підвищення якості сталі [Підручник] / О.Г. Величко, О.М. Стоянов, Б.М. Бойченко, К.Г. Нізяєв. - Дніпропетровськ: Середняк Т.К., 2016. - 196 с.

4. Влияние технологии внепечной обработки на загрязнённость стали неметаллическими включениями / А.В. Зиборов, В.В. Зырянов, М.С. Кузнецов, С.А. Кулагин [и др.] // Металлург. - 2008. - № 3. - С. 39-40.

5. Влияние параметров внепечной обработки стали $\mathrm{St} 10$ на загрязненность непрерывнолитой заготовки (круг 180 мм) неметаллическими включениями / Ф. Сиддики, А.В. Кодак, П.М. Явтушенко, А.И. Троцан [и др.] // Процессы литья. - 2008. - № 1. - С. 38-40.

6. Оптимизация технологии внепечной обработки высокоуглеродистой стали с целью снижения содержания оксидных неметаллических включений / В.В. Эндерс, Д.С. Якшук, М.П. Гуляев, В.В. Пивцаев // ОАО «Черметинформация». Бюллетень «Черная металлургия». - 2003. - № 8. - С. 26-29.

7. Мастрюков Б.С. Теплофизика металлургических процессов [Учеб. для ВУЗов] / Б.С. Мастрюков. - М.: МИСИС, 1996. -268 с.

8. Фролов Ю.Г. Курс коллоидной химии. Поверхностные явления и дисперсные системы: Учеб. для ВУЗов [2-е изд., перераб и доп.] / Ю.Г. Фролов. - М.: Химия, 1988. - 464 с. 